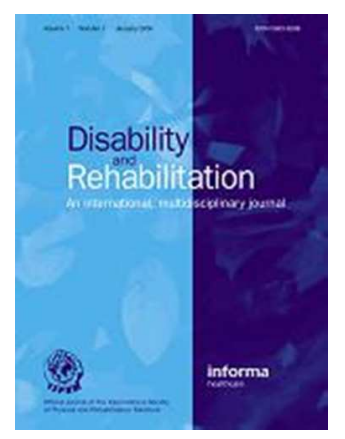

\title{
Linking the EASY-Care Standard to the International Classification of Functioning, Disability and Health
}

\begin{tabular}{|r|l|}
\hline Journal: & Disability and Rehabilitation \\
\hline Manuscript ID: & TIDS-12-2012-032.R1 \\
\hline Manuscript Type: & Research Paper \\
\hline Keywords: & $\begin{array}{l}\text { EASY-Care Standard, International Classification of Functioning, Disability } \\
\text { and Health, Elderly, Quality of Life }\end{array}$ \\
\hline \multicolumn{2}{|c}{} \\
\hline
\end{tabular}




\section{Implications for Rehabilitation}

- The integration of the universal language of the ICF in the EASY-Care potentiates the use of this comprehensive instrument in assessing older people needs at primary care settings.

- The information obtained with the EASY-Care Standard can be worldwide understood and can be used to plan rehabilitation interventions at community settings for older adults.

15
16
17
18
19
20
21
22
23
24
25
26
27
28
29
30
31
32
33
34
35
36
37
38
39
40
41
42
43
44
45
46
47
48
49
50
51
52
53
54
55
56
57
58
59
60




\section{Abstract}

2

Purpose: This study aimed to document the content of the EASY-Care Standard questionnaire to the International Classification of Functioning, Disability and Health (ICF) and present its ICF Core Set.

4 Method: The EASY-Care was linked to the ICF by two trained health professionals according to the

5 established linking rules. The agreement between the health professionals was determined using the

6 Cohen's kappa.

7

Results: The agreement between the two health professionals was almost perfect for each level of the ICF (Cohen's kappas between 0.91 and 0.97 ). The 65 items of the EASY-Care were linked to 61 different ICF categories, $16(26 \%)$ from the Body functions component, 3 from the Body structures (5\%), 30 from the Activities and participation (49\%) and 12 from the Environmental factors (20\%). Twelve concepts could not be linked to the ICF at all: 6 were classified as Personal factors, 1 as not defined-general health and 5 were not classified.

Conclusions: The integration of the universal language of the ICF in the EASY-Care illustrates the potential of use this instrument in primary care settings at community level.

15 Keywords: EASY-Care Standard; International Classification of Functioning, Disability and Health; 16 Elderly; Quality of Life. 
2 In 2009, an estimate of 737 million people worldwide were 60 years old or over [1]. This number is 3 projected to increase to 2 billion in 2050, by which time older people will be outnumbering children 4 (people aged 0 to 14 years). The demographic change poses huge challenges to primary and 5 community care settings, as populations age chronic disease rates also rise [2]. According to the 6 World Health Organization (WHO), preventive health care and screening for early disease detection 7 and management has been considered a priority in the primary health care setting at the community 8 level. However, there are significant time limitations in primary care [3], and thus health and social 9 professionals tend to use measures of health care utilization instead of health and social outcomes or quality of life [4], despite knowing that there is much room for improvement in quality of geriatric care 11 [3].

12 To overcome these difficulties the Elderly Assessment System (EASY-Care), a quick and comprehensive assessment instrument, which enables a multidimensional health and social assessment of older people (over 64 years old), has been developed [5]. The EASY-Care is recommended by the WHO [5] since it "establishes a link with quality of life concepts and the measurement of subjective well-being" [6 p. 197]. The instrument also measures independence, risk of falls, risk of breakdown in care, depression and cognitive impairment. These subscores are prior determinants for defining needs and care planning in this population. The reliability, validity and costeffectiveness of this instrument has been tested across the globe and appears to be high, which facilitates its incorporation into routine practice in primary and community care settings [7]. However, without its contents being mapped to the International Classification of Functioning, Disability and Health (ICF), which is the common language for describing health and health-related states, the results cannot be compared with the ones obtained from other measures (e.g., Barthel Index) and which mapping to ICF has already been performed [8]. A national and international database about functioning and health, needs instruments such as EASYCare to develop an ICF Core Set to describe functioning and disability of older people. This core set can also include categories that are not been covered by ICF however, are considered crucial for older people. This may contribute for the development of a new construct of what is functioning and disability among older people.

30 The ICF can guide content analyses of the different measures and enhance the interpretation of data 
1 content of the EASY-Care has never been linked to the ICF. Therefore, this study aimed to examine

2 the content of EASY-Care Standard questionnaire to the ICF.

\section{Methods}

4 A study was conducted to identify the ICF categories that best described the content of each item of

5 the EASY-Care Standard.

6 Instruments

7 EASY-Care Standard

8 The EASY-Care Standard was developed on behalf of the European Regional office of the WHO [5] 9 and has been validated for 15 languages [9]. The instrument consists of a set of brief questionnaires 10 or single items derived from well-established instruments, i.e., Barthel Index [10], Duke OARS IADL 11 Scale [11], Short Form (36) Health Survey (SF-36) [12], a brief cognitive impairment test [13], the four12 item geriatric depression scale [14] and the WHO 11 countries survey instrument [15]. It promotes a common approach, based on person-centred care and multidisplinary practice which focuses more on the quality of life of the older person rather than on his/her illnesses. Its domains include Seeing, Hearing \& Communicating; Looking after yourself; Getting around; Your safety, Your accommodation and finance; Staying healthy; Your mental health and well-being; Information related with medication. Higher scores in each domain mean a worse perception of functioning and well-being. It also generates scores for risk of breakdown in care, risk of falls, level of (in)dependence, depression and cognitive impairment screening being particularly useful within the context of primary care and people living in the community. It can be completed as a self-assessment or by practitioner in an interview. In this study, we used the Portuguese version of EASY-Care Standard [16]. ICF

The ICF is a general health status framework [6]. It has two parts, each with two components: part 1 Functioning and Disability, with Body functions, Body structures and Activities and participation components; and part 2 - Contextual Factors, with Environmental factors and Personal factors. The ICF uses an alphanumeric system in which the letters $b, s, d$ and $e$ are used to denote Body functions, Body structures, Activities and participation, and Environmental factors, respectively. These letters are followed by a numeric code that starts with the chapter number, which corresponds to the first level ( 1 digit), followed by the second level (2 digits), and the third and fourth levels ( 1 digit each). Personal factors are not yet classified in ICF. Therefore, four lists of categories can be obtained to characterise Body functions, Body structures, Activities and participation and Environmental factors. 


\section{$1 \quad$ Linking procedures}

2 The 65 items of the EASY-Care were linked to the ICF according to published linking rules $[8,17,18]$.

3 Two health professionals, physiotherapists, trained in applying ICF as well as in the linking rules, 4 independently linked each concept included in the EASY-Care to the most precise ICF category. The 5 linking process was divided into three phases: phase 1 - identification of the meaningful concepts, a 6 short sentence or expression that describe a concrete aspect of functioning; phase 2 - linking the 7 meaningful concepts to the ICF code and category; and phase 3 - organisation of the ICF categories 8 comprised in the EASY-Care.

9 When the same item comprised different constructs, it was linked to more than one ICF category. 10 Items that clearly referred to Personal factors, as defined in the ICF, but the meaningful concept is not 11 contained and coded in the ICF, were identified as pf (personal factor). If the information provided by 12 the meaningful concept was not sufficient for making a decision about the most precise ICF category, items should be assigned $n d$ (not definable). The meaningful concepts referring to quality of life in general were assigned $n d-g h$ (not definable-general health). Finally, if the meaningful concept is not contained in the ICF and it is not a personal factor, this meaningful concept is assigned $n c$ (not covered).

17 Data analysis

The agreement between the two health professionals was determined with the Cohen's kappa for each level of the ICF classification [19]. The value of Cohen's kappa ranges from 0 to 1 and can be categorised as: slight agreement $(0.0-0.20)$, fair agreement $(0.21-0.40)$, moderate agreement $(0.41-$ $0.60)$, substantial agreement $(0.61-0.80)$ and almost perfect agreement $(\geq 0.80)$ [20]. All statistical analyses were performed using PASW Statistics (Version 18.0, SPSS Inc., Chicago, IL). Disagreements were discussed and a consensus obtained.

24

\section{Results} Inter-observer agreement

The inter-observer agreement between the two health professionals was almost perfect for the ICF component $(0.91 ; 95 \% \mathrm{Cl} 0.83-0.98)$, first $(0.97 ; 95 \% \mathrm{Cl} 0.92-1)$, second $(0.95 ; 95 \% \mathrm{Cl} 0.90-1)$ and third level (0.97; 95\% Cl 0.89-1), with Cohen's kappa.

30 The concepts included in the 65 items of the EASY-Care were linked to 61 ICF categories, 2 from the 31 first level, 35 from the second level and 24 from the third level. 
Insert table 1 about here

2

3

4

5

6

7

8

9

10

11

Looking to the Body functions component, it is observed that the EASY-Care present 14 connections to Chapter Mental functions $(7.3,7.5,7.7,7.8,7.9,7.11,7.12,7.13$ and the six questions of the cognitive impairment test), 3 connections to Chapter Sensory functions and pain (1.1, 1.2 and 7.6), 1 connection to Chapter Functions of Cardiovascular, haematological, immunological and respiratory systems (6.2), 1 connection to Chapter Functions of digestive, metabolic and endocrine systems (2.13), 1 connection to Chapter Genitourinary and reproductive functions (2.12) and 1 connection to Chapter Skin and related structures functions (2.11). Chapters Voice and speech functions and Neuromusculoskeletal and movement-related functions are not comprised in the EASY-Care. However, the Body structures related to these Body functions are addressed, i.e., Chapter Structures involved in voice and speech (2.8) and Chapter Structures related with the movement (3.2).

The majority of items of the EASY-Care were linked to the Activities and participation component, with 1 connection to Chapter Learning and applying knowledge (1.2), 2 connections to Chapter Communication (1.3 and 1.4), 6 connections to Chapter Mobility (3.1, 3.3, 3.4, 3.6, 3.8 and 8.3), 16 connections to Chapter Self-care $(2.1,2.2,2.3,2.4,2.7,2.9,2.10,2.14,6.1,6.3,6.4,6.5,6.6,6.7,8.1$ and 8.2), 4 connections to Chapter Domestic life (question 9 from personal information, 2.5, 2.6 and 3.7), 8 connections to Chapter Major life areas (questions 6 and 8 from the personal information, 5.3 and 7.1), and 1 connection to Chapter Community, social and civic life (7.1). There are no connections to Chapters General tasks and demands and Interpersonal interactions and relationships.

The EASY-Care includes items linked to all chapters of the Environmental factors component: 6 connections to Chapter Products and technology (questions 3 and 6 from personal information, 5.1, 5.2 and 8.4), 1 connection to Chapter Natural environment and human-made changes to environment (questions 3 from personal information), 7 connections to Chapter Support and relationships (questions 10 from personal information and 4.5), 2 connection to Chapter Attitudes (questions 4.3 and 4.4.) and 1 connection to Chapter Services, systems and policies (question 5.4).

There is only one question of the EASY-Care (question 1.2) related with hearing difficulties that was linked to two different ICF Components, Body functions (b230 Hearing functions) and Activities and participation (d115 Listening).

Moreover, some identified concepts $(n=12)$ could not be linked to the ICF. Six concepts - sex, age, current marital status, years of formal education, living arrangements and professional status - were identified as Personal factors. Item 7.2 (In general, would you say your health is) is a meaningful 
1 concept referred to quality of life in general, and was assigned $n d$-gh (not defined-general health).

2 Falls (3.5), security at home (4.1), security outside (4.2), dead of a relative (7.4) and satisfaction with

3 life (7.10) were assigned $n c$ (not covered), because they are not contained in the ICF.

\section{$4 \quad$ ICF Categories}

5 The EASY-Care was linked to 61 ICF codes, 16 (26\%) from the Body functions component, 3 from the 6 Body structures (5\%), 30 from the Activities and participation (49\%) and 12 from the Environmental 7 factors $(20 \%)$ (table 2$)$.

8 Insert table 2 about here

\section{Discussion}

10 This study presented an analysis of the content of the EASY-Care Standard using the ICF as reference. Most of the content of the EASY-Care was linked to the ICF, demonstrating good content validity. Therefore, despite the well-known advantages of this instrument, particularly that it enables a multidimensional health and social assessment of older people and it is a practical tool to be used in primary care, this study shows that the results obtained with this instrument can be worldwide understood and compared as it is compatible with the standard language of the ICF.

All ICF components are contained in this instrument, with Body functions and Activities and participation components being particularly well covered. Regarding Body functions, Mental functions and Sensory functions and pain, which are related to the aging process [21,22], are very well covered by the EASY-Care. Voice and speech functions and Neuromusculoskeletal and movement-related functions, where muscle power and endurance are included, are not covered. These functions were considered relevant to include in the Generic Set [23] and in the ICF Core Set for geriatric patients in early post-acute rehabilitation facilities [24]. However, older people may experience voice and movement changes due to the aging process of laryngeal and skeletal muscle structures [25,26]. These Body structures (Chapter Structures involved in voice and speech and Chapter Structures related with the movement) are represented in the EASY-Care. Cardiovascular diseases are a major cause of mortality and morbidity among older people $[27,28]$. However, neither the functions nor structures of the cardiovascular system are covered by a specific item in the EASY-Care. This information is possible to collect in the Medical History section, specifically in the summary of current medical conditions. However, the inclusion of items addressing cardiovascular impairments should be considered in future modifications of the EASY-Care. 
1 The Activities and participation component is the most represented in the EASY-Care, demonstrating

2 that one of the main concerns of this instrument is to assess the experience of older people in different

3 life domains. The activities related to self-care, major life areas and mobility are the ones most

4 covered. Self-care and mobility are basic activities of daily living that are frequently restricted in older

5 people $[29,30]$. In the ICF Core Set for geriatric patients in early post-acute rehabilitation facilities

6 these activities were also those most represented in the Activities and participation component [24].

7 Surprisingly, Chapter Interpersonal Interactions and Relationships, where family and intimate

8 relationships are included, is not addressed by the EASY-Care. Despite family relationships not being

9 covered, the support received from immediate and extended family are possible to assess with this

10 instrument. However, regarding intimate relationships, they are not addressed. Intimate relationships,

11 specifically sexuality, are recognized to be an important factor for older people, affecting identity,

12 sense of self, mental health, social relationships and quality of life [31]. To obtain a more complete

13 picture of the older people level of activity and participation, evaluations performed by the EASY-Care

should be supplemented by ICF categories, such as $d 760$ family relationships and $d 770$ intimate relationships.

The EASY-Care includes items linked to all chapters of the Environmental factors component, demonstrating that it enables the description of the context in which older people live. Chapters Products and technology and Support and relationships were those most represented, showing that the EASY-Care favours the individual's most immediate environment rather than the general environment [6].

21 Six concepts were linked to Personal factors (sex, age, current marital status, years of formal education, living arrangements and professional status) and are relevant to consider in the assessment and management of older people. These Personal factors may contribute to the classification of this component in future revisions of the ICF. A meaningful concept referred to quality of life in general was assigned not defined-general health. Quality of life is a broad concept affected by the person's physical health, psychological state, level of independence, social relationships, personal beliefs and their relationship with their environment [32]. Probably due to this complexity, the concept of quality life is not currently integrated in the ICF, however, this should be considered in future revisions of this classification. Other five identified concepts - falls, security at home, security outside, dead of a relative and satisfaction with life - are not covered by any specific ICF category.

31 This highlights a major ICF limitation since it cannot include all individual experiences with the level of 
1 specification required. Nevertheless, regarding falls, as this is considered a worldwide major issue 2 affecting older people [33], the addition of this concept should be considered.

3 The list of ICF categories comprised in the EASY-Care provides an overview of what we are currently assessing in older people with this comprehensive assessment instrument. In future, this list of 5

6 categories, together with categories of other measures, may contribute to develop a comprehensive ICF Core Set to describe functioning of older people.

7 Study limitations

\section{Declaration of interest}

21 The authors report no declarations of interest.

22

\section{References}

24 1. United Nations. World Population Ageing 2009. New York: United Nations; 2009.

25 2. World Health Organization. Towards age-friendly primary health care. Geneva: World Health Organization; 2004.

3. Wenger NS, Solomon DH, Roth CP, al. e. The quality of medical care provided to vulnerable community-dwelling older patients. Annals of internal medicine 2003;139(9):740-747.

4. Johri $\mathrm{M}$, Beland $\mathrm{F}$, Bergman $\mathrm{H}$. International experiments in integrated care for the elderly: a synthesis of the evidence. International journal of geriatic psychiatry 2003;18(3):222-235. 
15 . Philip I. Can a medical and social assessment be combined? Journal of the Royal Society of

2 Medicine 1996;90:11-13.

6. World Health Organization. International Classification of Functioning, Disability and Health. Geneva: World Health Organization; 2001.

7. Olde-Rikkert MGM, Long JF, Philp I. Development and evidence base of a new efficient assessment instrument for international use by nurses in community settings with older people. International Journal of Nursing Studies 2012:1-4 [Epub ahead of print].

8. Stucki G, Kostanjsek N, Ustun B, Cieza A. ICF-based classification and measurement of functioning. European Journal of Physical and Rehabilitation Medicine 2008;44(3):315-328.

9. Sousa L, Galante H, Figueiredo D. Qualidade de vida e bem-estar dos idosos: um estudo exploratório na população portuguesa. Revista de saúde pública 2003;37(3):364-371.

10. Mahoney F, Barthel D. Functional evaluation: the Barthel Index. Maryland State Medical Journal 1965;14:56-61.

11. Fillenbaum GG, Smyer MA. The development, validity and reliability of the OARS multidimensional functional assessment questionnaire. Journal of Gerontology $1981 ; 36(4): 428-434$.

12. Brazier JE HR, Jones NMB, O'Cathain A, Thomas KJ, Usherwood T, Westlake L.,. Validating the SF-36 health survey questionnaire: new outcome measure for primary care. British Medical Journal 1992;305(6846):160-164.

13. Katzman R BT, Fuld P, Peck A, Schechter R, Schimmel H.,. Validation of a short orientationmemory-concentration test of cognitive impairment. American Journal of Psychiatry 1983;140(6):734-739.

14. D'Ath P KP, Mullan E, Evans S, Katona C.,. Screening, detection and management of depression in elderly primary attenders: the acceptability and performance of the 15 item geriatric depression scale (GDS15) and the development of short versions. Family Practice 1994;11(3):260-266.

15. Heikkinen E, Waters WE, Brzezinski ZJ. The Elderly in Eleven Countries: A Sociomedical Survey. World Health Organization Regional Office for Europe, Public Health in Europe, Copenhagen 1983;21.

16. The EASY-Care Foundation. EASY-Care Standard 2010: Sistema de Avaliação de Pessoas Idosas. <http://www.easycare.org.uk/images/files/countries 8 1.pdf>. 
1 17. Cieza A, Brockow T, Ewert T, Amman E, Kollerits B, Chatterji S, Ustun TB, Stucki G. Linking

2

3

4

5

6

7

8

9

10

11

12 health-status measurements to the international classification of functioning, disability and health. Journal of Rehabilitation Medicine 2002;34(5):205-210.

18. Cieza A, Geyh S, Chatterji S, Kostanjsek N, Ustun B, Stucki G. ICF linking rules: an update based on lessons learned. Journal of Rehabilitation Medicine 2005;37(4):212-218.

19. Elliott AC, Woodward WA. Statistical analysis quick reference guidebook: With SPSS examples. California: Sage Publications, Inc.; 2007.

20. Landis JR, Koch GG. The Measurement of Observer Agreement for Categorical Data. Biometrics 1977;33(1):159-174.

21. Burns A, Zaudig M. Mild cognitive impairment in older people. The Lancet 2002;360(9349):1963-1965.

22. Jakobsson U, Klevsgård R, Westergren A, Hallberg IR. Old people in pain: A comparative study. Journal of Pain and Symptom Management 2003;26(1):625-636.

23. Cieza A, Geyh S, Chatterji S, Kostanjsek N, Ustun B, Stucki G. Identification of candidate categories of the International Classification of Functioning Disability and Health (ICF) for a Generic ICF Core Set based on regression modelling. BMC Medical Research Methodology 2006;6(1):36.

24. Grill E, Hermes R, Swoboda W, Uzarewicz C, Kostanjsek N, Stucki G. ICF Core Set for geriatric patients in early post-acute rehabilitation facilities. Disability and Rehabilitation 2005;27(7-8):411-7.

25. Ramig LO, Gray S, Baker K, Corbin-Lewis K, Buder E, Luschei E, Coon H, Smith M. The Aging Voice: A Review, Treatment Data and Familial and Genetic Perspectives. Folia Phoniatrica et Logopaedica 2001;53(5):252-265.

26. Nair KS. Aging muscle. The American Journal of Clinical Nutrition 2005;81(5):953-963.

27. Yazdanyar A, Newman AB. The burden of cardiovascular disease in the elderly: morbidity, mortality, and costs. Clinics in geriatric medicine 2009;25(4):563-77, vii.

28. Cabrera MA, de Andrade SM, Mesas AE. A prospective study of risk factors for cardiovascular events among the elderly. Clinical interventions in aging 2012;7:463-8.

29. Webber SC, Porter MM, Menec VH. Mobility in Older Adults: A Comprehensive Framework. The Gerontologist 2010;50(4):443-450. 
1 30. Dale B, Söderhamn U, Söderhamn O. Self-care ability among home-dwelling older people in

2

3

4 31. Heath H. Older people in care homes: sexuality and intimate relationships. Nursing older 5

$6 \quad$ 32. World Health Organization. WHOQOL User Manual. World Health Organization; 1998.

7 33. World Health Organization. WHO global report on falls prevention in older age. Geneva: World 
Table 1 - Linking the EASY-Care to the ICF.

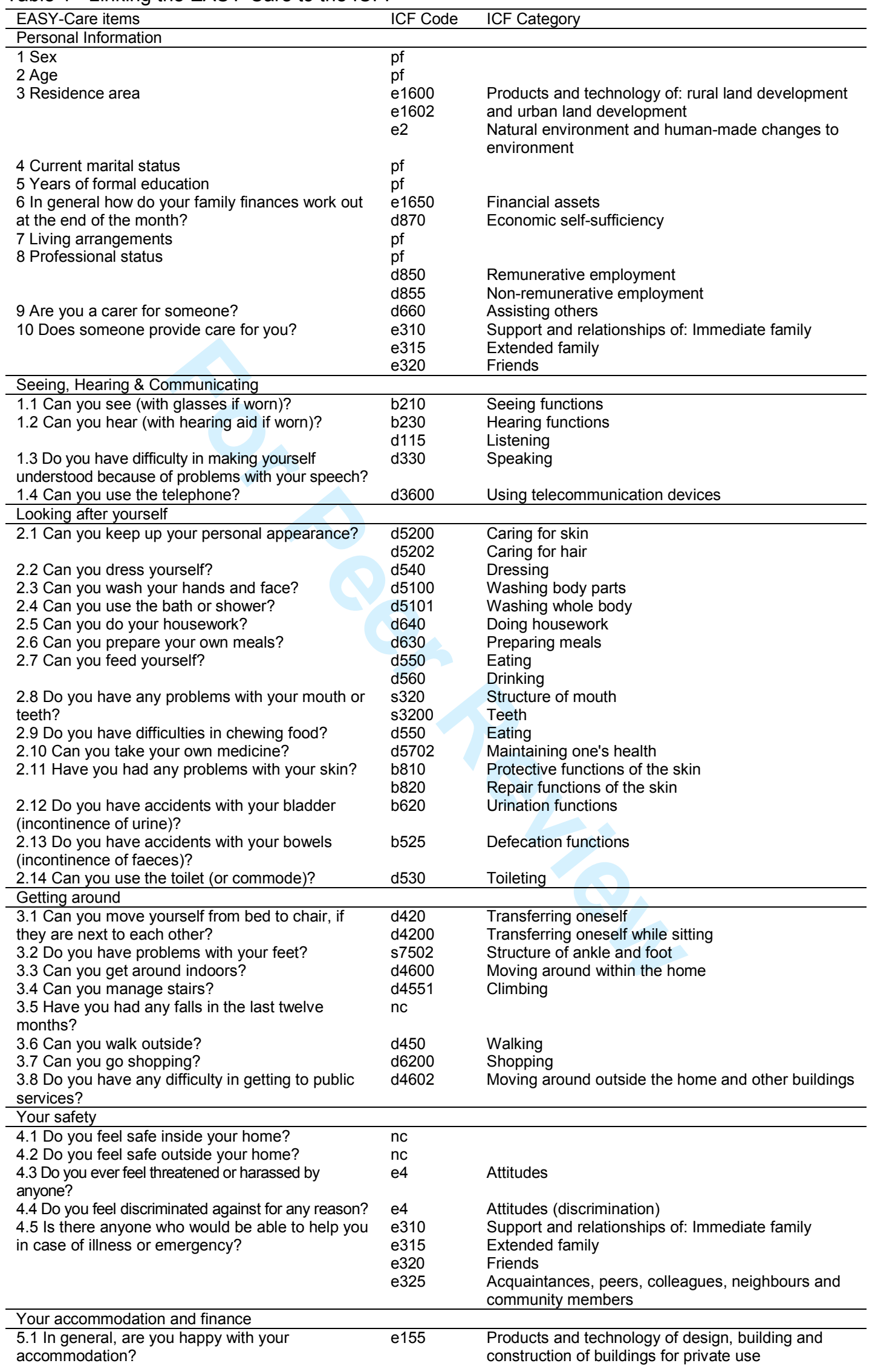


5.2 In general, would you say that your accommodation is:

5.3 Are you able to manage your money and financial affairs?

5.4 Would you like advice about financial allowances or benefits?

Staying healthy

6.1 Do you take regular exercise?

6.2 Do you get out of breath during normal activities?

6.3 Do you smoke any tobacco?

6.4 Do you think you drink too much alcohol?

6.5 Has your blood pressure been checked recently?

6.6 Do you have any concerns about your weight?

6.7 Do you think you are up to date with your

vaccinations?

Your mental health and well-being

7.1 Are you able to pursue leisure interests

hobbies, work and learning activities which are important to you?

7.2 In general, would you say your health is:

7.3 Do you feel lonely?

7.4 Have you suffered from any recent loss or bereavement?

7.5 Have you had any trouble sleeping in the past month?

7.6 Have you had bodily pain in the past month? 7.7 During the last month, have you often been bothered by feeling down, depressed or hopeless?

7.8 During the last month, have you often been bothered by having little interest or pleasure in doing things?

7.9 Do you have any concerns about memory loss or forgetfulness?

Geriatric Depression Scale

7.10 Are you basically satisfied with your life? nc

7.11 Do you feel that your life is empty? b152

7.12 Are you afraid that something bad is going to b152 happen to you?

7.13 Do you feel happy most of the time?

Other information concerned with medication

8.1 Do you need help to regularly get your

medications?

8.2 Do you always take your medications according to your doctor recommendations?

8.3 Can you take all your medications out of the packaging?

8.4 Do you think that some of your medications could be more effective if took in a different way?

Cognitive impairment test

1 What is the year?

2 What is the month?

3 What time is it?

b1140

5 I would like you to say the months backward. b1720

6 Repeat the memory phrase.

pf: personal factor; nc: not covered; nd-gh: not defined-general health.

b1441

Products and technology of design, building and

construction of buildings for private use

Basic economic transactions

Complex economic transactions

Economic self-sufficiency

Social security services, systems and policies

Managing diet and fitness

Sensations associated with cardiovascular and respiratory functions

d5702 Maintaining one's health (avoiding harms to health,

d5702 like tobacco)

d5702 Maintaining one's health (regular physical

examinations)

Maintaining one's health (immunizations)

d920 Recreation and leisure

d850 Remunerative employment

Non-remunerative employment

b152 Emotional functions

nc

b134 Sleep functions

b2800 Generalized pain

b152 Emotional functions

b1301 Motivation

$144 \quad$ Memory functions

Emotional functions

Emotional functions

Emotional functions

d5702 Maintaining one's health (seeking professional

assistance for medication)

Maintaining one's health (following medical and other health advice about medication)

d440 Fine hand use

e1101 Drugs

1140 Orientation to time

b1140 Orientation to time

Orientation to time

Simple calculation

Simple calculation

Long-term memory 
Table 2 - List of ICF codes comprised in the EASY-Care.

\begin{tabular}{|c|c|}
\hline $\begin{array}{l}\text { ICF } \\
\text { code }\end{array}$ & ICF category \\
\hline \multicolumn{2}{|c|}{ Body functions } \\
\hline b1140 & Orientation to time \\
\hline b1141 & Orientation to place \\
\hline b1301 & Motivation \\
\hline b134 & Sleep functions \\
\hline b144 & Memory functions \\
\hline b1441 & Long-term memory \\
\hline b152 & Emotional functions \\
\hline b1720 & Simple calculation \\
\hline b210 & Seeing functions \\
\hline b230 & Hearing functions \\
\hline b2800 & Generalized pain \\
\hline b460 & $\begin{array}{l}\text { Sensations associated with cardiovascular and } \\
\text { respiratory functions }\end{array}$ \\
\hline b525 & Defecation functions \\
\hline b620 & Urination functions \\
\hline b810 & Protective functions of the skin \\
\hline b820 & Repair functions of the skin \\
\hline \multicolumn{2}{|c|}{ Body structures } \\
\hline s320 & Structure of mouth \\
\hline s3200 & Teeth \\
\hline s7502 & Structure of ankle and foot \\
\hline \multicolumn{2}{|c|}{ Activities and participation } \\
\hline d115 & Listening \\
\hline d330 & Speaking \\
\hline d3600 & Using telecommunication devices \\
\hline d420 & Transferring oneself \\
\hline d4200 & Transferring oneself while sitting \\
\hline d440 & Fine hand use \\
\hline d450 & Walking \\
\hline d4551 & Climbing \\
\hline d4600 & Moving around within the home \\
\hline d4602 & Moving around outside the home and other buildings \\
\hline d5100 & Washing body parts \\
\hline d5101 & Washing whole body \\
\hline d5200 & Caring for skin \\
\hline d5202 & Caring for hair \\
\hline d530 & Toileting \\
\hline d540 & Dressing \\
\hline d550 & Eating \\
\hline d560 & Drinking \\
\hline d5701 & Managing diet and fitness \\
\hline d5702 & Maintaining one's health \\
\hline d6200 & Shopping \\
\hline d630 & Preparing meals \\
\hline d640 & Doing housework \\
\hline d660 & Assisting others \\
\hline d850 & Remunerative employment \\
\hline d855 & Non-remunerative employment \\
\hline d860 & Basic economic transactions \\
\hline d865 & Complex economic transactions \\
\hline d870 & Economic self-sufficiency \\
\hline d920 & Recreation and leisure \\
\hline \multicolumn{2}{|c|}{ Environmental factors } \\
\hline e1101 & Drugs \\
\hline e155 & $\begin{array}{l}\text { Products and technology of design, building and } \\
\text { construction for private use }\end{array}$ \\
\hline e1600 & Products and technology of rural land development \\
\hline e1602 & Products and technology of urban land development \\
\hline e1650 & Financial assets \\
\hline e2 & $\begin{array}{l}\text { Natural environment and human made changes to } \\
\text { environment }\end{array}$ \\
\hline e310 & Support and relationships of immediate family \\
\hline e315 & Support and relationships of extended family \\
\hline e320 & Support and relationships of friends \\
\hline e325 & $\begin{array}{l}\text { Support and relationships of acquaintances, peers, } \\
\text { colleagues, neighbours and community members }\end{array}$ \\
\hline e4 & Attitudes \\
\hline e570 & Social security services, systems and policies \\
\hline
\end{tabular}

